\title{
Berberine hydrochloride: anticancer activity and nanoparticulate delivery system
}

\author{
This article was published in the following Dove Press journal: \\ International Journal of Nanomedicine \\ 29 August 201I \\ Number of times this article has been viewed
}

\section{Wen Tan \\ Yingbo Li \\ Meiwan Chen \\ Yitao Wang}

State Key Laboratory of Quality Research in Chinese Medicine, Institute of Chinese Medical Sciences, University of Macau, Macao Special Administrative Region, China
Correspondence: Yitao Wang

State Key Laboratory of Quality Research in Chinese Medicine, Institute of Chinese Medical Sciences, University of Macau, Av Padre Tomas Pereira SJ, Taipa, Macao Special Administrative Region, China Tel +8538397469l

Fax +8532884 I358

Email ytwang@umac.mo

Meiwan Chen

State Key Laboratory of Quality Research in Chinese Medicine, Institute of Chinese Medical Sciences, University of Macau, Av Padre Tomas Pereira SJ, Taipa, Macao Special Administrative Region, China $\mathrm{Tel}+85383974873$

Fax $+8532884 \quad 358$

Email mwchen@umac.mo
Background: Berberine hydrochloride is a conventional component in Chinese medicine, and is characterized by a diversity of pharmacological effects. However, due to its hydrophobic properties, along with poor stability and bioavailability, the application of berberine hydrochloride was hampered for a long time. In recent years, the pharmaceutical preparation of berberine hydrochloride has improved to achieve good prospects for clinical application, especially for novel nanoparticulate delivery systems. Moreover, anticancer activity and novel mechanisms have been explored, the chance of regulating glucose and lipid metabolism in cancer cells showing more potential than ever. Therefore, it is expected that appropriate pharmaceutical procedures could be applied to the enormous potential for anticancer efficacy, to give some new insights into anticancer drug preparation in Chinese medicine.

Methods and results: We accessed conventional databases, such as PubMed, Scope, and Web of Science, using "berberine hydrochloride", "anti-cancer mechanism", and "nanoparticulate delivery system" as search words, then summarized the progress in research, illustrating the need to explore reprogramming of cancer cell metabolism using nanoparticulate drug delivery systems.

Conclusion: With increasing research on regulation of cancer cell metabolism by berberine hydrochloride and troubleshooting of issues concerning nanoparticulate delivery preparation, berberine hydrochloride is likely to become a natural component of the nanoparticulate delivery systems used for cancer therapy. Meanwhile, the known mechanisms of berberine hydrochloride, such as decreased multidrug resistance and enhanced sensitivity of chemotherapeutic drugs, along with improvement in patient quality of life, could also provide new insights into cancer cell metabolism and nanoparticulate delivery preparation.

Keywords: berberine hydrochloride, anticancer mechanisms, nanoparticulate drug progress

\section{Introduction}

Berberine hydrochloride is an isoquinoline alkaloid (see Figure 1) isolated from a variety of Chinese herbs, including Coptidis rhizoma, Phellodendron chinense schneid, and Phellodendron amurense, and has diverse pharmacological actions. It has antidiabetic and antilipid peroxidation activity, as well as an anti-atherosclerotic action, and also has neuroprotective properties and improves polycystic ovary syndrome. ${ }^{1-5}$ Berberine hydrochloride is widely used as an antibacterial, antifungal, and anti-inflammatory drug, and has been used as a gastrointestinal remedy for thousands of years in China. ${ }^{6,7}$

Nowadays, the antiproliferative activity and sensitivity enhancement of berberine hydrochloride in various cancer cell lines ${ }^{8-14}$ have led to further research interest in 


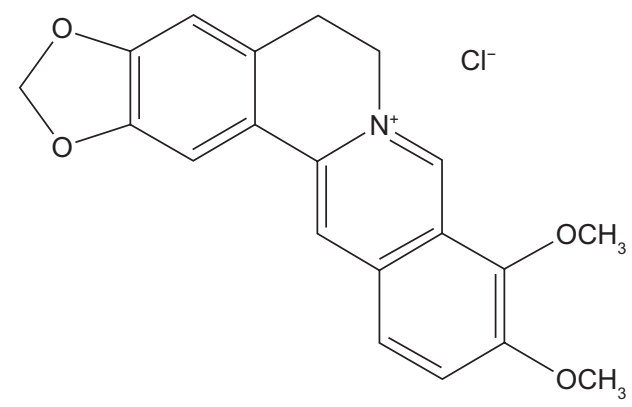

Figure I Chemical structure of berberine hydrochloride.

this compound. ${ }^{15-17}$ Its antineoplastic properties include induction of apoptosis and cell cycle arrest, along with inhibition of cell migration and invasion via regulation of multiple pathways. ${ }^{18-21}$ The potential targets of berberine hydrochloride include reactive oxygen species generation, mitochondrial function, DNA topoisomerase inhibition, DNA or RNA binding, the estrogen receptor, matrix metalloproteinase regulation, p53 activation, and NF-kappa B signal activation. ${ }^{10,22-26}$ However, it has poor water solubility caused by a quarternary amine, resulting in a low effective concentration and limited absorption in the gastrointestinal tract, which seriously limits its application and development as a pharmaceutical preparation. Furthermore, it has a risk of adverse reactions associated with intramuscular and intravenous administration, such as anaphylactic shock and drug rash, so a novel drug delivery system to improve the solubility and bioavailability of berberine hydrochloride has become a matter of urgency.

During the rapid development of nanotechnology, increasing attention has been paid to nanoparticulate drug delivery systems. ${ }^{27-29}$ Modern nanoparticulate dosage forms including polymeric nanoparticles, nanocapsules, liposomes, solid lipid nanoparticles, and nanoemulsions, all of which can improve drug solubility. In general, nanoparticulate drug delivery enhances solubility and bioavailability, improving pharmacological activity and tissue macrophage distribution, while preventing physical and chemical degradation..$^{30,31}$ Therefore, we combined the good anticancer efficacy of berberine hydrochloride with a novel nanoparticulate drug delivery system to obtain a promising anticancer agent.

This review discusses anticancer mechanisms, with particular reference to regulation of glucose and lipid metabolism, and describes a novel drug delivery system for berberine hydrochloride, aiming to provide new insights into Chinese medicine preparations with anticancer activity.

\section{Anticancer mechanisms of berberine hydrochloride}

The potential antitumor activity of berberine hydrochloride has always been a subject of considerable interest because of its known ability to interact with nucleic acids. Its ability to bind specifically to oligonucleotides and to stabilize DNA triplexes or G-quadruplexes via telomerase and topoisomerase inhibition accounts for its antiproliferative activity. ${ }^{32,33}$ The predominant interaction between berberine hydrochloride and double-stranded or single-stranded DNA is electrostatic, and can be quantified in terms of the Hill model of cooperative interactions. ${ }^{34}$ Recent novel mechanisms have a higher propensity for autophagy and autophagic regulators. Wang et al found that berberine hydrochloride induced autophagic cell death which was diminished by 3-methyladenine, a cell death inhibitor, in the human hepatic carcinoma cell lines HepG2 and MHCC97-L, through activation of beclin-1 and inhibition of the mTOR signaling pathway. ${ }^{35}$ In addition, the autophagic marker, microtubule-associated protein-1 light chain 3 (LC3) was modified after administration of berberine hydrochloride in the human A549 lung cancer cell line, accompanied by shrinkage of tumor volume in a Lewis lung carcinoma model in mice, all of which indicates that autophagy might be important in cancer cell death. ${ }^{36}$

In addition to autophagy and its interaction with nucleic acid, the hypoglycemic and hypolipidemic effects of berberine hydrochloride also point to a relationship between adipose tissue/adipocytes and tumorigenesis, through upregulation of mRNA and protein levels in adipose tissue, including peroxisome proliferator-activated receptor (PPAR) $\alpha, \beta$, and $\gamma, \mathrm{CDK} 9$, and cyclin T1. ${ }^{3}$ Adipose tissue and adipocytes have a significant role in the tumor microenvironment, ${ }^{37}$ and SPARC (secreted protein acidic and rich in cysteine), an adiposity inhibitor, was suggested by Nagaraju and Sharma ${ }^{38}$ to be a potent anticancer molecule, and human adipose tissuederived stem cells are known to be a source of carcinomaassociated fibroblasts in the presence of transforming growth factor $\beta 1 .^{39}$ Further, adipose tissue-derived vascular endothelial growth factor and leptin promote adipogenesis in order to maintain the tumor microenvironment. ${ }^{40}$ Hirano et al have also suggested the existence of undefined factors derived from cancer cells which promote adipogenesis, further indicating a potential relationship between adipogenesis and development of cancer. ${ }^{41}$ In clinical lipofilling procedures undertaken for patients with breast cancer, there is an urgent need to clarify the issue of cancer recurrence and adipogenesis. ${ }^{42}$ The adipogenesis positive regulator, PPAR $\gamma$, 
overexpressed in ERBB2-positive breast cancer cells, enables fatty acid synthesis, mainly to support energy demands and cell survival. ${ }^{43}$ Therefore, less toxic PPAR $\gamma$ agonists or antagonists, including berberine hydrochloride, are regarded as potential agents for improving adipose breast tissue and decreasing breast cancer risk, as well as suppressing proliferation and invasion of cancer cells. ${ }^{44}$ By inhibiting PPAR $\gamma$ protein expression and increasing PPAR $\alpha$ mRNA levels, berberine hydrochloride has been shown to improve free fatty acid-induced insulin resistance in myotubes, and to suppress adipogenesis in white preadipocytes in humans and hepatic insulin resistance in diabetic hamsters. ${ }^{2,45,46}$ Berberine hydrochloride also prevented wasting of epididymal adipose tissue and ameliorated cancer cachexia in colon 26/clone 20 -transplanted mice and colon 26/clone 20 cells, ${ }^{47}$ further highlighting the beneficial effect of this compound on adipose tissue in the tumor microenvironment.

Working as a potential natural compound in cancer therapy via its interaction with nucleic acid and regulation of cancer cells, as well as induction of autophagy, berberine hydrochloride augments the effects of chemotherapy/ radiotherapy and has shown good prospects in cancer treatment. ${ }^{11}$ After the novel mechanisms by which it interferes with the development of adipose tissue and adipocyte metabolism in the tumor microenvironment were investigated, the efficacy and potential applications of berberine hydrochloride were highlighted and emphasized. Moreover, its extensive occurrence in various plant species and low toxicity suggest that berberine hydrochloride has the potential to become an effective antitumor agent in the future.

\section{Nanoparticulate delivery systems}

Reports on nanoparticulate delivery systems for berberine hydrochloride can be divided into three types, ie, solid lipid nanoparticles, nanoemulsions, and liposomes. Preparation, characterization, experimental design methods, and in vivo and in vitro studies are summarized here.

The first nanoparticulate delivery system uses a conventional rotary-evaporated film-ultrasonication method to make solid lipid nanoparticles of berberine hydrochloride (BH-SLN). These have good stability, a mean diameter of $60.5 \mathrm{~nm}$, a zeta potential of $29.7 \mathrm{mV}$, drug loading of $8.69 \%$, and an entrapment ratio of $97.58 \% .{ }^{48}$ Certain other factors have a direct impact on actual amount and quality of liposome entrapment, including preparation and manufacturing methods, and types of excipients used and particle size. Entrapment is defined as the fraction of the initial solution remaining within the liposomes, which is the key factor in clinical application. ${ }^{49}$ Wang et al established the method of coagulation centrifugation to determine the entrapment efficiency of BH-SLN. ${ }^{50}$ A saturated aqueous solution of sodium chloride $0.05 \mathrm{~mL}$ in BH-SLN $0.5 \mathrm{~mL}$ was determined by high-pressure liquid chromatography, and then centrifuged at $12,000 \mathrm{rpm}$ for 10 minutes to obtain the supernatant. The results show that coagulation centrifugation was rapid and accurate.

The second delivery system is berberine hydrochloride nanoemulsion, made by isopropyl myristate, EL40, and glycerin using pseudoternary phase diagrams. The nanoemulsion is a clear transparent solution with an average particle diameter of $56.8 \mathrm{~nm} .{ }^{51}$ Small spherical drops are seen under electron microscopy, with a stable content and diameter even under high humidity and temperature conditions, along with strong light, $92.5 \%$ humidity, a temperature range of $40^{\circ} \mathrm{C}-60^{\circ} \mathrm{C}$, and $(4500 \pm 500) \mathrm{LX}$.

The last system is a liposomal one, and there are several approaches used to prepare berberine hydrochloride liposomes, including the thin film evaporation method, the active loading method, and a combination of the thin film evaporation and active loading methods. The thin film evaporation process could achieve a higher encapsulation efficiency, and the optimum manufacturing processes are characterized by $60^{\circ} \mathrm{C}$ of hatched temperature, 30 minutes of time, and $3.3 \mathrm{mg} / \mathrm{mL}$ of cholesterol concentration. ${ }^{52}$ An active loading method is better than passive loading with a higher entrapment efficiency. ${ }^{53}$ There are several factors to be considered, including addition sequence, incubation time, incubation temperature, $\mathrm{pH}$ value of the external water phase, and the particle size of the liposome. Changing the addition sequence can also achieve different entrapment efficiencies, as can increasing incubation time and temperature and decreasing the particle size. ${ }^{53}$ Chen et al used different individual variables and an orthogonal design to obtain the optimal preparation conditions for berberine hydrochloride liposomes, including incubation time and incubation temperature, proportional weights of drug and lipids, soybean phosphatidylcholine, and cholesterol. ${ }^{54}$ The results indicated that the average encapsulation efficiency of the optimized liposome was $78.51 \% \pm 2.45 \%$, with a size range of 2.2-3.5 $\mu \mathrm{m}$. Based on the uniform design, berberine hydrochloride liposomes were prepared by thin film evaporation and an active loading method. ${ }^{55}$ An optimal formulation was established and a high encapsulation efficiency of $79.33 \%$ was obtained with a drug loading 
ratio of 30.21 and a size range of 2.2-3.8 $\mu \mathrm{m}$. In vivo and in vitro studies were carried out to investigate the way in which liposomal berberine hydrochloride works. Gou et al studied the effects of berberine hydrochloride liposomes on the combination of impaired glucose tolerance and hyperlipidemia, suggesting that glucose and lipid metabolism was interfered with and progression from hyperlipidemia to type 2 diabetes was also prevented. ${ }^{56}$

\section{Conclusion}

Studies of the molecular mechanisms by which berberine hydrochloride affects lipid and glucose metabolism warrant further attention. Additionally, with the increasing research on reprogramming of cancer cell metabolism, including inhibition of glycolysis, impairment of mitochondrial function, and suppression of cell anabolism, it could be possible to reverse abnormal cancer cell metabolism in various ways, including blocking formation of the cell membrane and synthesis of macromolecules, and inhibiting growth and proliferation of cancer cells. During the process of interfering with cancer cell reprogramming, because of the alteration in the physiological properties of the cell, multidrug resistance, sensitivity of chemotherapeutic drugs, and patient quality of life could be ameliorated, which indicates the potential of berberine hydrochloride as an adjuvant drug in antineoplastic treatment. With effective troubleshooting of issues such as the hydrophobic properties, poor stability, and bioavailability of berberine hydrochloride, research on nanoparticulate delivery systems for this compound is being vigorously pursued. Furthermore, investigations in this field are likely to provide new insights into anticancer drug preparation in Chinese medicine.

\section{Acknowledgments}

This study was supported by the Macao Science and Technology Development Fund (029/2007/A2) and University of Macau Research Fund (UL016A/09-Y2/CMS/ WYT01/ICMS).

\section{Disclosure}

The authors report no conflicts of interest in this work.

\section{References}

1. Lee IA, Hyun YJ, Kim DH. Berberine ameliorates TNBS-induced colitis by inhibiting lipid peroxidation, enterobacterial growth and NF-kappaB activation. Eur J Pharmacol. 2010;648(1-3):162-170.

2. Liu X, Li G, Zhu H, et al. Beneficial effect of berberine on hepatic insulin resistance in diabetic hamsters possibly involves in SREBPs, LXRalpha and PPARalpha transcriptional programs. Endocr J. 2010; 57(10):881-893.
3. Zhou J, Zhou S. Berberine regulates peroxisome proliferator-activated receptors and positive transcription elongation factor $\mathrm{b}$ expression in diabetic adipocytes. Eur J Pharmacol. 2010;649(1-3):390-397.

4. Wu M, Wang J, Liu LT. Advance of studies on anti-atherosclerosis mechanism of berberine. Chin J Integr Med. 2010;16(2):188-192.

5. Zhao L, Li W, Han F, et al. Berberine reduces insulin resistance induced by dexamethasone in theca cells in vitro. Fertil Steril. 2011;95(1): 461-463.

6. Remppis A, Bea F, Greten HJ, et al. Rhizoma coptidis inhibits LPSinduced MCP-1/CCL2 production in murine macrophages via an AP-1 and NFkappaB-dependent pathway. Mediators Inflamm. 2010; 2010:194896.

7. Liu F, Liang HL, Xu KH, Tong LL, Tang B. Supramolecular interaction of ethylenediamine linked beta-cyclodextrin dimer and berberine hydrochloride by spectrofluorimetry and its analytical application. Talanta. 2007;74(1):140-145.

8. Choi MS, Yuk DY, Oh JH, et al. Berberine inhibits human neuroblastoma cell growth through induction of p53-dependent apoptosis. Anticancer Res. 2008;28(6A):3777-3784.

9. Ho YT, Lu CC, Yang JS, et al. Berberine induced apoptosis via promoting the expression of caspase- $8,-9$ and -3 , apoptosis-inducing factor and endonuclease $\mathrm{G}$ in SCC-4 human tongue squamous carcinoma cancer cells. Anticancer Res. 2009;29(10):4063-4070.

10. Hsu WH, Hsieh YS, Kuo HC, et al. Berberine induces apoptosis in SW620 human colonic carcinoma cells through generation of reactive oxygen species and activation of JNK/p38 MAPK and FasL. Arch Toxicol. 2007;81(10):719-728.

11. Patil JB, Kim J, Jayaprakasha GK. Berberine induces apoptosis in breast cancer cells (MCF-7) through mitochondrial-dependent pathway. Eur J Pharmacol. 2010;645(1-3):70-78.

12. Auyeung KK, Ko JK. Coptis chinensis inhibits hepatocellular carcinoma cell growth through nonsteroidal anti-inflammatory drug-activated gene activation. Int J Mol Med. 2009;24(4):571-577.

13. Yu FS, Yang JS, Lin HJ, et al. Berberine inhibits WEHI-3 leukemia cells in vivo. In Vivo. 2007;21(2):407-412.

14. James MA, Fu H, Liu Y, Chen DR, You M. Dietary administration of berberine or Phellodendron amurense extract inhibits cell cycle progression and lung tumorigenesis. Mol Carcinog. 2011;50(1):1-7.

15. Kim DW, Ahan SH, Kim TY. Enhancement of arsenic trioxide (As(2) $\mathrm{O}(3)$ )-mediated apoptosis using berberine in human neuroblastoma SH-SY5Y cells. J Korean Neurosurg Soc. 2007;42(5):392-399.

16. Shen N, Li CN, Huan Y, Shen ZF. [Advances of the mechanism study on berberine in the control of blood glucose and lipid as well as metabolism disorders.] Yao Xuе Xие Bao. 2010;45(6):699-704. [Chinese.]

17. Zhang Q, Xiao X, Feng K, et al. Berberine moderates glucose and lipid metabolism through multipathway mechanism. Evid Based Complement Alternat Med. September 26, 2010. [Epub ahead of print].

18. Singh T, Vaid M, Katiyar N, Sharma S, Katiyar SK. Berberine, an isoquinoline alkaloid, inhibits melanoma cancer cell migration by reducing the expressions of cyclooxygenase-2, prostaglandin $\mathrm{E}$ and prostaglandin E receptors. Carcinogenesis. 2011;32(1):86-92.

19. Li-Weber M. Targeting apoptosis pathways in cancer by Chinese medicine. Cancer Lett. August 2, 2010. [Epub ahead of print].

20. Tsang CM, Lau EP, Di K, et al. Berberine inhibits Rho GTPases and cell migration at low doses but induces G2 arrest and apoptosis at high doses in human cancer cells. Int J Mol Med. 2009;24(1):131-138.

21. Zhang X, Gu L, Li J, et al. Degradation of MDM2 by the interaction between berberine and DAXX leads to potent apoptosis in MDM2overexpressing cancer cells. Cancer Res. 2010;70(23):9895-9904.

22. Meeran SM, Katiyar S, Katiyar SK. Berberine-induced apoptosis in human prostate cancer cells is initiated by reactive oxygen species generation. Toxicol Appl Pharmacol. 2008;229(1):33-43.

23. Pandey MK, Sung B, Kunnumakkara AB, Sethi G, Chaturvedi MM, Aggarwal BB. Berberine modifies cysteine 179 of IkappaBalpha kinase, suppresses nuclear factor-kappaB-regulated antiapoptotic gene products, and potentiates apoptosis. Cancer Res. 2008;68(13): $5370-5379$. 
24. Qin Y, Pang JY, Chen WH, Zhao ZZ, Liu L, Jiang ZH. Inhibition of DNA topoisomerase I by natural and synthetic mono- and dimeric protoberberine alkaloids. Chem Biodivers. 2007;4(3):481-487.

25. Lin JP, Yang JS, Wu CC, et al. Berberine induced down-regulation of matrix metalloproteinase-1, -2 and -9 in human gastric cancer cells (SNU-5) in vitro. In Vivo. 2008;22(2):223-230.

26. Katiyar SK, Meeran SM, Katiyar N, Akhtar S. p53 Cooperates berberine-induced growth inhibition and apoptosis of non-small cell human lung cancer cells in vitro and tumor xenograft growth in vivo. Mol Carcinog. 2009;48(1):24-37.

27. Yang RS, Chang LW, Yang CS, Lin P. Pharmacokinetics and physiologically-based pharmacokinetic modeling of nanoparticles. J Nanosci Nanotechnol. 2010;10(12):8482-8490.

28. Seigneuric R, Markey L, Nuyten DS, et al. From nanotechnology to nanomedicine: Applications to cancer research. Curr Mol Med. 2010; 10(7):640-652.

29. Kurmi BD, Kayat J, Gajbhiye V, Tekade RK, Jain NK. Micro- and nanocarrier-mediated lung targeting. Expert Opin Drug Deliv. 2010; 7(7):781-794.

30. Kumar CSSR. Nanotechnology tools in pharmaceutical R\&D. Mater Today. 2010;12:24-30.

31. Raffa V, Vittorio O, Riggio C, Cuschieri A. Progress in nanotechnology for healthcare. Minim Invasive Ther Allied Technol. 2010;19(3): 127-135.

32. Maiti M, Kumar GS. Polymorphic nucleic acid binding of bioactive isoquinoline alkaloids and their role in cancer. $J$ Nucleic Acids. December 15, 2009. [Epub ahead of print].

33. Bhadra K, Kumar GS. Therapeutic potential of nucleic acid-binding isoquinoline alkaloids: Binding aspects and implications for drug design. Med Res Rev. January 14, 2010. [Epub ahead of print].

34. Tian X, Song Y, Dong H, Ye B. Interaction of anticancer herbal drug berberine with DNA immobilized on the glassy carbon electrode. Bioelectrochemistry. 2008;73(1):18-22.

35. Wang N, Feng Y, Zhu M, et al. Berberine induces autophagic cell death and mitochondrial apoptosis in liver cancer cells: The cellular mechanism. J Cell Biochem. 2010;111(6):1426-1436.

36. Peng PL, Kuo WH, Tseng HC, Chou FP. Synergistic tumor-killing effect of radiation and berberine combined treatment in lung cancer: The contribution of autophagic cell death. Int J Radiat Oncol Biol Phys 2008;70(2):529-542.

37. Masson O, Prebois C, Derocq D, et al. Cathepsin-d, a key protease in breast cancer, is up-regulated in obese mouse and human adipose tissue, and controls adipogenesis. PLoS One. 2011;6(2):e16452.

38. Nagaraju GP, Sharma D. Anti-cancer role of SPARC, an inhibitor of adipogenesis. Cancer Treat Rev. January 13, 2011. [Epub ahead of print].

39. Jotzu C, Alt E, Welte G, et al. Adipose tissue-derived stem cells differentiate into carcinoma-associated fibroblast-like cells under the influence of tumor-derived factors. Anal Cell Pathol. 2010;33(2): 61-79.

40. Vona-Davis L, Rose DP. Angiogenesis, adipokines and breast cancer. Cytokine Growth Factor Rev. 2009;20(3):193-201.
41. Hirano T, Morii H, Nakazawa K, et al. Enhancement of adipogenesis induction by conditioned media obtained from cancer cells. Cancer Lett. 2008;268(2):286-294.

42. Lohsiriwat V, Curigliano G, Rietjens M, Goldhirsch A, Petit JY. Autologous fat transplantation in patients with breast cancer: "silencing" or "fueling" cancer recurrence? Breast. February 4, 2011. [Epub ahead of print].

43. Kourtidis A, Srinivasaiah R, Carkner RD, Brosnan MJ, Conklin DS. Peroxisome proliferator-activated receptor-gamma protects ERBB2positive breast cancer cells from palmitate toxicity. Breast Cancer Res. 2009;11(2):R16.

44. Carter JC, Church FC. Obesity and breast cancer: The roles of peroxisome proliferator-activated receptor-gamma and plasminogen activator inhibitor-1. PPAR Res. 2009;2009:345320.

45. Chen Y, Li Y, Wang Y, Wen Y, Sun C. Berberine improves free-fatty-acid-induced insulin resistance in L6 myotubes through inhibiting peroxisome proliferator-activated receptor gamma and fatty acid transferase expressions. Metabolism. 2009;58(12):1694-1702.

46. Hu Y, Davies GE. Berberine inhibits adipogenesis in high-fat diet-induced obesity mice. Fitoterapia. 2010;81(5):358-366.

47. Iizuka N, Hazama S, Yoshimura K, et al. Anticachectic effects of the natural herb Coptidis rhizoma and berberine on mice bearing colon 26/clone 20 adenocarcinoma. Int J Cancer. 2002;99(2):286-291.

48. Hou J, Zhou S. Optimization of the preparation technology of berberine hydrochloride solid lipid nanoparticles by orthogonal experiment. China Pharmacy. 2008;19(15):1150-1152.

49. Gruner SM, Lenk RP, Janoff AS, Ostro MJ. Novel multilayered lipid vesicles: Comparison of physical characteristics of multilamellar liposomes and stable plurilamellar vesicles. Biochemistry. 1985;24(12): 2833-2842.

50. Wang Y, Zheng J, Xu B, Wang H, Deng Y, Bi D. Determination of entrapment efficiency of berberine hydrochloride solid lipid nanoparticles by coagulation-centrifuge method. Journal of Zhengzhou University (Medical Sciences). 2009;44(1):188-189.

51. Sun H, Ouyang W. Preparation and physicochemical characteristics of berberine hydrochloric nanoemulsion. Chinese Traditional and Herbal Drugs. 2007;38(10):1476-1480.

52. Zhang F, An X. Study on preparation of berberine hydrochloride liposomes. Journal of Nanjing Normal University (Natural Science). 2006;29(1):56-58.

53. Deng Y, Wang S, Wu Q, Wan F, Lei X, Wang Z. Preparation of berberine hydrochloride liposomes by active loading method. Chinese Pharmaceutical Journal. 2004;39(1):40-42.

54. Chen J, Tan L, Li W, Li G. Study on the preparation process of berberine hydrochloride liposomes by orthogonal design. Journal of Practical Medical Techniques. 2007;14(14):1868-1870.

55. Tan L, Li G, Chen J, Su W, Rong K. Application of uniform design for preparation of berberine hydrochloride liposomes. Journal of Practical Medical Techniques. 2007;14(11):1385-1386.

56. Ju S, Tan L, Su W, Rong K. Interventional effect of berberine liposome on impaired glucose tolerance accompanied with hyperlipemia. Journal of Practical Traditional Chinese Medicine. 2007;23(8):490-492.
International Journal of Nanomedicine

\section{Publish your work in this journal}

The International Journal of Nanomedicine is an international, peerreviewed journal focusing on the application of nanotechnology in diagnostics, therapeutics, and drug delivery systems throughout the biomedical field. This journal is indexed on PubMed Central,

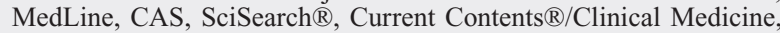

\section{Dovepress}

Journal Citation Reports/Science Edition, EMBase, Scopus and the Elsevier Bibliographic databases. The manuscript management system is completely online and includes a very quick and fair peer-review system, which is all easy to use. Visit http://www.dovepress.com/ testimonials.php to read real quotes from published authors. 